\title{
E-government Adoption: A Cultural Comparison
}

\author{
Lemuria Carter \\ School of Business and Economics \\ North Carolina Agricultural \& Technical State University \\ 1601 East Market Street \\ Greensboro, NC 27411 \\ Vishanth Weerakkody \\ School of Information Systems, Computing and Mathematics \\ Brunel University \\ Uxbridge \\ Middlesex UB8 3PH, UK
}

This is the author's accepted manuscript of an article published in Information Systems Frontiers, 10(4), 473-482, 2008, which has been published in final form at http://link.springer.com/article/10.1007\%2Fs10796-008-9103-6. 


\section{Abstract}

E-government diffusion is an international phenomenon. This study compares e-government adoption in the U.K. to adoption in the U.S. In particular, this study seeks to determine if the same factors are salient in both countries. Several studies have explored citizen acceptance of egovernment services in the U.S. However, few studies have explored this phenomenon in the U.K To identify the similarities and differences between the U.K. and the U.S. a survey is conducted in the U.K. and the findings are compared to the literature that investigates diffusion in the U.S. This study proposes a model of e-government adoption in the U.K. based on salient factors in the U.S. A survey is administered to 260 citizens in London to assess the importance of relative advantage, trust and the digital divide on intention to use e-government. The results of binary logistic regression indicate that there are cultural differences in e-government adoption in the U.K. and the U.S. The results indicate that of the prevailing adoption constructs, relative advantage and trust are pertinent in both the U.S. and the U.K., while ICT adoption barriers such as access and skill may vary by culture. Implications for research and practice are discussed.

Keywords: e-government, technology adoption, trust, digital divide, residential, consumer 


\section{Introduction}

E-government diffusion is an international phenomenon. According to a global study conducted by comScore there are over 694 million Internet Users worldwide. In light of the increased ubiquity of e-government, most countries, including the United States (U.S.) which accounted for the largest number of Internet users (152 million users) and the United Kingdom (U.K.) which rounded out the top five with over 30 million users, are eager to increase citizen acceptance of this innovation (comScore 2006).

According to Hofstede (2003) the U.K. and the U.S. are very similar on several cultural dimensions. Hofstede uses five dimensions to present cultural comparisons for over 70 countries. These dimensions assess citizen views of power, individualism, masculinity, uncertainty and virtue. Using a scale from 1 100, each country is assigned a score. The U.K. and the U.S. were among the few countries ( 7 out of 70) to score highest on individualism. Regarding the other four cultural dimensions, the scores for the U.K. and the U.S. only differed by an average of 5.5 points (out of 100).

In addition to cultural similarities, the U.S. and the U.K. also share technological similarities. A 2004 European Union (EU) report ranked both the U.S. and the U.K. in the top tier of its e-government readiness index (European Union 2004). However, despite the UK e-enabling many of its services, its government is encountering several barriers to e-government adoption (Al-Sebie and Irani 2005; Weerakkody and Choudrie 2005). A study by Gilbert et al. (2004) indicates that citizens' potential usage of e-government services in the U.K. is extremely low (Gilbertet al. 2004). Despite marketing efforts to increase awareness many local government councils in the U.K. (www.direct.gov.uk) have stated that the usage of their services is sparse (Adeshara et al. 2004). Cross (2007) reports that a $£ 5 \mathrm{~m}$ campaign to persuade citizens to contact their local council via the central e-government web portal (www.direct.gov.uk) has had little effect in the UK. Recently, the UK government launched a media campaign to spread awareness of e-government services and to encourage citizens to connect to their local council websites. However, website usage statistics published by the Society for IT management, a consultancy established by the association of local government IT managers, suggest that the campaign raised 
awareness of local government websites but that the increase in demand for services was too small to measure. The figures, collected from 59 council websites, show that Directgov lags far behind commercial search engines as a first port of call to government (Cross 2007).

An earlier study by the Department for Education and Skills (DfES) in 2005 based on a survey of 6,000 UK online centres (which were mainly set up during the period 1999-2002 to help bridge the digital divide) also shows that egovernment usage in the UK is low (SQW Limited and MORI Social Research Institute 2005). As part of the study, UK online centre users were introduced to the concept of a government website, and were then asked whether they would access such a website if specific help and training were offered in a UK online centre. According to this research, over half (56\%) suggested that they would use the service at a centre, and a further $30 \%$ stated that they would learn how to use the website at a centre but then access it elsewhere. However, one in ten (11\%) users also suggested that they would not use the website at all. Although this study implies that usage levels are low it also suggests that there would be enthusiasm and demand from centre users for e-government services if support and advice was available (DfES 2005).Other research by the European Commission's Eurostat service has found that the UK is behind Germany, Sweden, Norway, Iceland and Finland in the number of individuals interacting online with public authorities. According to this research the UK is also behind most EU countries in the number of businesses obtaining information and transacting with the government over the Internet. According to the European Commission, 31 percent of businesses get information from the government online in the UK placing the country behind Sweden (90 percent), Italy (51 percent), Lithuania (63 percent) and Poland (57 percent) in this category (Kablenet 2005).

Several studies have explored e-government acceptance in the United States. And researchers are beginning to explore e-government in the U.K. Choudrie and Dwivedi (2005) administer a survey to assess citizen awareness of e-government services. Adeshara et al. (2004) explore e-government adoption by small and medium sized businesses. However, few studies have examined the factors that influence U.K. citizens' adoption of e-services in the public sector. Lee et al. (2005) state that cross-national research on e-government is sparse in 
the literature. Dwivedi et al. (2006) highlights the need for studies that investigate the adoption rate and behaviour of the UK citizens. This study attempts to fill this gap by integrating constructs from the diffusion of innovation theory, online trust and the Information Communication Technology (ICT) divide to compare the predictors of e-government adoption in the U.S. and the U.K. In particular, this study uses existing literature to develop a model of e-government adoption in the U.K. This model is then tested on citizens in the U.K. to determine which factors are significant across cultures. It is anticipated that this research will stimulate discussion among the e-government research community, particularly in the UK and the US, and provide some pointers to practitioners and policy makers in the two countries for improving e-government adoption.

This paper is divided into seven sections that provide responses to the aims and contributions of the research in the following manner. The conceptual background and theoretical perspective that is applied in the research is described in the next two sections. This is followed by a summary of the method applied to carry out the research in the following section. The next section presents the results of the empirical research followed by a discussion of the findings in the subsequent section. Finally, the conclusion of this research and their implications for e-government adoption is offered together with suggestions for future research directions in the final section.

\section{Background Literature}

\section{Technology Adoption}

There are numerous theories that seek to explain individual adoption of new technology. Davis' (1989) technology acceptance model (TAM) and Rogers' (Rogers 2003) diffusion of innovation theory (DOI) are two models commonly used to study user adoption of information systems. TAM, which is based on the theory of reasoned action (TRA), has two major constructs: perceived usefulness (PU) and perceived ease of use (PEOU) - which influence one's intention to use a system. Perceived usefulness was originally defined by Davis as the belief that using a particular system would enhance one's job performance. Perceived ease of use refers to one's perceptions of the amount of effort required to use the system. The model predicts that higher perceptions of usefulness and ease of use will increase intention to use a system. All other things being equal, perceived 
ease of use is predicted to influence perceived usefulness, since the easier a system is to use, the more useful it can be (Davis 1989).

Unlike TAM, which refers specifically to technology adoption, Rogers (2003) conceptualizes a generic theory of adoption: the diffusion of innovation theory (DOI). An innovation refers to a new concept or technology. Diffusion refers to the dissemination of an innovation into society. Rogers' theory identifies five constructs that influence a potential adopter's decision: relative advantage, complexity, compatibility, trialability and observability. Relative advantage refers to the belief that a new system has benefits above and beyond the current system. Complexity refers to perceptions of difficulty associated with adopting a system. Compatibility posits that one will be more likely to adopt an innovation if it is consistent with his values, views, beliefs, and customs. Trialability posits that one will be more likely to adopt an innovation if it can be tried out before actually committing to it. And observability suggests that one will be more likely to adopt an innovation if its benefits are visible and tangible. TAM constructs are included in the DOI model; perceived ease of use is represented by complexity and perceived usefulness is captured by relative advantage (Plouffe et al. 2001; Venkatesh et al. 2003).

Venkatesh et al. (2003) introduce UTAUT, the unified theory of acceptance and use of technology, which combines eight behavioral models of technology adoption: the theory of reasoned action, the technology acceptance model, the motivational model, the theory of planned behavior, a model combining the technology acceptance model and the theory of planned behavior, the model of PC utilization, the innovation diffusion theory, and the social cognitive theory. According to UTAUT, three constructs have a direct effect on usage intentions: effort expectancy (complexity), performance expectancy (relative advantage), and social influence. Social influence is defined as the degree to which an individual believes others think he should use a new technology. A fourth construct, facilitating conditions has a direct impact on actual usage. Facilitating conditions is not discussed in this paper since the construct of interest is intention to use.

Despite the numerous articles, models and constructs used to describe technology adoption Benbasat and Barki (2007) argue that only one construct consistently explains a large percent of the variance in use intentions: perceived 
usefulness, a.k.a. performance expectancy, a.k.a. relative advantage. The authors suggest future research should focus on the effects of this salient predictor of technology adoption since it alone is the most significant element of adoption models. Hence we include relative advantage in the proposed model to represent the technology adoption literature. Several studies of e-government adoption in the United States illustrate the importance of this construct (Careter and Belanger 2005; Gefen et al. 2005).

\section{Trust}

In addition to relative advantage, trust is also included in our egovernment adoption model. Recent studies of online behavior emphasize the importance of including trust in adoption models to gain a more comprehensive understanding of user acceptance of electronic services (Gefen et al. 2003; Gefen et al. 2005; Holsapple and Sasidharan 2005; Pavlou 2003; Pavlou and Fygenson 2006; Van Slyke et al. 2004). Rotter (1967) defines trust as an expectancy that the promise of an individual or group can be relied upon. Rotter's research is referenced in numerous studies of online trust (Mcknight et al. 2002).

According to the literature, e-government is in a nascent stage (Jaeger 2003; Lieth and Morison 2004). E-government has not yet matured; it is still growing. Hence, this study focuses on users' initial trust in an e-government service. Initial trust refers to trust in a new trustee. Initial trust is necessary in a relationship where the citizen does not yet have consequential information about the e-service provider. In initial relationships people use whatever information they have, such as opinions of the online interface or the government agency, to assess the credibility of the trustee (Mcknight et al. 2002). During initial encounters, trust is largely based on characteristics of the trustor, assumptions made about the traits of the trustee, and institutional factors (Grazioli and Jarbenpaa 2000).

The literature states that there are two objects of trust. First, one must trust the entity providing the service. Secondly, one must trust the mechanism through which the service is provided (Tan and Theon 2001). Hence, e-government users should evaluate the characteristics of the government agency and characteristics of the underlying technology before using an electronic-service (Pavlou 2003). Therefore, trust in e-government has two components: trust in a specific entity 
(trust of the government) and trust in the enabling technology (trust of the Internet) (Carter and Belanger 2005; Pavlou 2003).

Trust of the Internet is a salient predictor of e-service adoption (Bhattachaerjee 2002; Carter and Belanger 2005; Mcknight et al. 2002; Navarra and Cornford 2003; Pavlou 2003; Warekentin et al. 2002; Welch et al. 2005). In the literature, it is commonly referred to as institution-based trust. It refers to an individual's perceptions of the institutional environment, including the parameters and directives that make an environment feel safe (Mcknight et al. 2002). According to Zucker (1986), institution-based trust is one of the most important forms of trust in distal environments where sensitive information is shared. Pavlou et al. (2003) suggest that the Internet is such an environment.

The e-service literature, both e-commerce and e-government, uses the institutional view of trust (Carter and Belanger 2005; Mcknight et al. 2002; Pavlou 2003; Warekentin et al. 2002; Welch et al. 2005). McKnight and Chervany (2002) suggest that the popularity of the institution is a result of ecommerce uniting many diverse organizations. According to Shapiro (1987) institution based trust is essentially trust in the Internet: trust in the security measures and performance structures of this electronic medium. E-government adoption is dependent upon citizens' belief that the Internet is a reliable technology.

Citizen confidence in the government agency's ability to provide online services is also imperative to the diffusion of e-government initiatives. Trust of the government refers to one's perceptions regarding the authenticity and aptitude of the agency providing the service (Becerra and Gupta 1999; Ganesan and Hess 1997; Jarvenpaa et al. 1998; Lee and Turban 2001; Mayer et al. 1995; McKnight et al. 1998; McKnight et al. 2002). Gefen et al. (2005) state that trust in the agency has a major impact on the use of a technology. In order to support egovernment initiatives, citizens must believe government agencies possess the technical skills necessary to execute and secure e-government systems. Transparent, accurate, reliable interaction with e-government service providers will augment citizen confidence and acceptance of e-government services. On the contrary, broken promises and fraudulent behavior from government officials and employees will decrease confidence and increase resistance to e-government programs. 
Trust has proven to be an integral part of e-government adoption (Carter and Belanger 2005; Warekentin et al. 2002; Welch et al. 2005). Oxendine et al. (2003) compare citizen adoption of electronic networks in different regions of the U.S. They found that system adoption was more prominent in localities where citizens are more trusting. Due to the impersonal nature of the Internet, citizens must believe the agency providing the service is reliable. Wang and Emurian (2005) envisage that lack of trust is one of the most formidable barriers to eservice adoption, especially when financial or personal information is involved.

\section{The ICT Divide}

As governments worldwide increasingly implement e-government services, concerns about the potential impacts of a digital divide continue to grow. While definitions of the concept of the digital divide vary, it generally refers to the distinction between the ICT haves and have-nots: the difference between those who have Internet access and computer skills and those who do not. Regarding access, Internet connections are still not distributed evenly across racial, regional and socio-economic lines. According to Wright (2002) in 2001, 60 percent of white households in the U.S. had Internet access, while only 34 percent of African American and 38 percent of Latino households did. Similarly, roughly 78 percent of households with income between $\$ 50,000$ and $\$ 75,000$ had Internet access compared to only 40 percent of those with household incomes between $\$ 20,000$ and $\$ 25,000$. Thomas and Streib (2003) suggest that among Internet users, ethnicity and education are important predictors of which Internet users will also utilize government Web sites. Higher usage rates tend to exist among white citizens and individuals with high education levels. They surmise that government Web sites seem to draw an even more exclusive audience than the already somewhat elite audience for the Internet in general. Huang (2007) finds that in the U.S., counties' adoption of e-government is highly correlated with various socio-economic factors.

The ICT divide is even stronger for the skills needed to use technological innovations (Wellman and Haythornthwaite 2002). Mossenburg et al. (2003) suggest many people lack the basic skills needed to interact with computer hardware and software. Researchers have found that the old, less-educated, poor and minority individuals are more likely to need computer assistance, such as help using the keyboard or e-mail (Jackson et al. 2004). Even those who obtain basic 
computer skills are frequently unable to use a computer or the Internet to retrieve and interpret information (Mossenburg et al. 2003).

Belanger and Carter (2006) argue that there are two major types of ICT divides: an access divide and a skill divide. In this study we are interested in determining whether Internet access and skill also have an impact on egovernment adoption in the U.K. Hence, we include Internet Accessibility and Internet Skill in the proposed model. We are not seeking to identify the potential causes of these factors, such as age, income, etc. The purpose of this study is to determine if Internet access and skill are significant predictors of e-government adoption in the U.K. If these factors are significant, future research should explore them in greater detail.

\section{Research Model \& Hypotheses}

Based on the aforementioned literature, we propose the following model (see figure 1). This model indicates that relative advantage, trust, Internet accessibility and Internet skill all have a significant impact on intention to use an e-government service in the U.K. The hypotheses are presented in table 1.

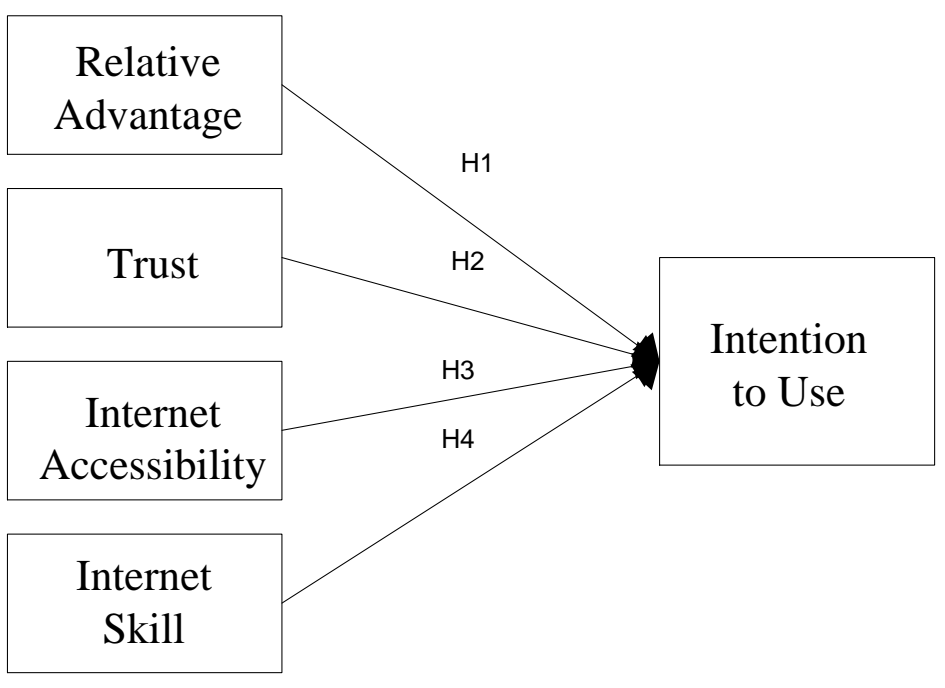

Figure 1. E-government Adoption Factors 


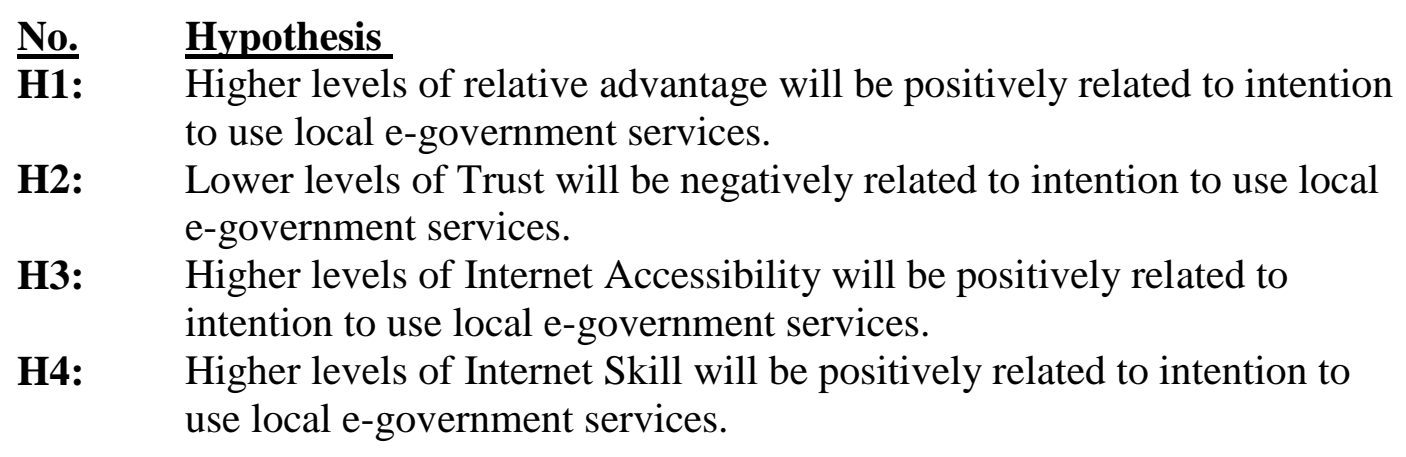

\section{Methodology}

\section{Data Collection}

To obtain citizen perceptions of e-government, a survey was administered in a local borough in North West London. Prior to conducting the survey a pretest was administered to three colleagues to evaluate the appropriateness of the survey questions. After making minor adjustments to question wording, the actual survey was conducted. Participants were obtained by approaching 352 members of the general public including neighbors, friends and family of one of the researchers and by soliciting responses from citizens at an outdoor shopping area in North West London. The researcher-completed survey method was employed. This approach allows the researcher to read questions to the citizen and then record the citizen's response. This method was chosen over a selfadministered survey to maximize the response rate. Previous research has shown that people are less likely to respond to surveys when they are distributed; response rates are normally less than $50 \%$ (Dwivedi et al. (2006). We targeted citizens age 21 and above, as previous research by Dwivedi et al. (2006) suggests $21-65$ is the ideal age range for e-government research.

The research protocol undertaken was as follows: firstly, the participants were approached and the purpose of the research was explained to them; secondly, the procedure that the participants had to follow during the administering of the questionnaire was explained; and finally the questions were posed to the participants and the answers were recorded by the researcher. This process took between six to ten minutes to complete. 


\section{Sample}

The borough of North West London where the research was conducted in the UK represents one of London's less affluent areas and is made up largely of ethnic minority (i.e. South Asian and African) citizens. From a total of 352 citizens approached for this research we obtained 260 participants (a response rate of 74 percent) from diverse age, gender and professional backgrounds. Nineteen percent of the participants were between the ages of $18-20,42$ percent between $21-30,23$ percent between 31-40, 11 percent between 41-50, and 5 percent were 50 and older. Hence, the majority of our sample is within the target age range of $21-65$ and the data collected represents a diverse sample. Seventy-five percent of the respondents use the Internet at least 4-5 times a week. Seventy-seven percent are aware that the Internet can be used to contact the local government and fifty-eight percent currently use the Internet to interact with their local government. Yet, most of the participants were unaware of the other ICT options for contacting their local government; ninety-eight percent did not know about kiosks and ninety-six percent did not know about mobile phone options.

\section{Instrument Development}

The proposed model includes four independent variables, relative advantage, Internet trust, Internet accessibility and Internet skill and one dependent variable, intention to use. Items were adapted from prior research on egovernment adoption (Carter and Belanger 2005). Citizens' provided their use intentions by responding to a Yes/No question that asked if they would use an egovernment service in the future. To test relative advantage we asked participants if e-government would increase their access to local council and if it would make it easier to access information from local government. To assess trust we asked participants to indicate if a lack of trust impedes their adoption of e-government services. Similarly, participants were also asked to indicate if a lack of Internet access and ICT skills had an impact on their use of e-government services.

Prior to performing the regression analysis, the relative advantage items were tested for reliability and validity. Chronbach's alpha was used to test reliability; this value was above the .70 suggested cut-off. A confirmatory factor analysis was used to evaluate construct validity. All items loaded on the proper construct. Each of the other constructs were measured with a single item. Also, a casewise list was used to check for outliers; none were found. 


\section{Data Analysis}

Data was analyzed using stepwise binary logistic regression using SPSS 15.0. The purpose of binary logistic regression is to estimate the impact of independent variables on a dichotomous dependent variable. We employed forward stepwise regression in order to determine the strongest indicators of use intention. To test a model using forward stepwise regression, the first $\mathrm{x}$ variable (where $\mathrm{x}$ is an independent variable) to enter the equation is the one that explains the largest amount of variance in y (where y is the dependent variable). The second $\mathrm{x}$ variable to enter is the one that explains the greatest amount of the remaining variance in $y$. This process is repeated until there are no more variables left that explain a significant percentage of the variance in $y$.

\section{Results}

The results indicate that two of the four hypotheses are significant. Relative advantage (RADV) and trust (NUTrust) both have a significant impact on intention to use e-government services. Citizens who recognize the benefits of e-government compared to traditional government options were more willing to use e-government services. Also, citizens who exhibit a lack of trust are less likely to use e-government services. The chi-square statistic is significant $\left(\mathrm{X}^{2}\right.$ $=294.921, \mathrm{p}=.000)$ indicating that the overall model is significant. The following table illustrates the variables included in the model at each step. Step 1 adds relative advantage to the model. Step 2 adds trust. The following table indicates a significant increase in the predictive power of the model as a result of adding both of these factors. The exclusion of Internet accessibility and skill indicate that they do not make a significant contribution to predicting use intention.

Table 2. Stepwise Regression Model

Model if Term Removed

\begin{tabular}{|c|c|c|c|c|c|}
\hline \multicolumn{2}{|l|}{ Variable } & $\begin{array}{l}\text { Model Log } \\
\text { Likelihood }\end{array}$ & $\begin{array}{l}\text { Change in } \\
-2 \text { Log } \\
\text { Likelihood }\end{array}$ & df & $\begin{array}{l}\text { Sig. of the } \\
\text { Change }\end{array}$ \\
\hline Step 1 & RADV & -168.448 & 275.585 & 1 & .000 \\
\hline Step 2 & RADV & -152.084 & 262.417 & 1 & .000 \\
\hline & NUIrust & -31.950 & 22.150 & 1 & .000 \\
\hline
\end{tabular}

a. Based on conditional parameter estimates 
The classification table below illustrates the predictive capability of the regression model at each step. In the final model, 81 cases are observed to be 0 and are correctly predicted to be $0 ; 169$ cases are observed to be 1 and are correctly predicted to be 1 . The table also shows how many cases are not correctly predicted (10 cases are observed to be 0 but are predicted to be 1 ). The overall percentage of cases that are correctly predicted by the model increases from 94.2 in step 1 to 96.2 for the full model.

Table 3. Classification Table

Classification Table

\begin{tabular}{|c|c|c|c|c|c|}
\hline & & & \multicolumn{3}{|c|}{ Predicted } \\
\hline & & & \multicolumn{2}{|c|}{ USE } & \multirow{2}{*}{$\begin{array}{c}\text { Percentage } \\
\text { Correct }\end{array}$} \\
\hline \multicolumn{3}{|c|}{ Observed } & 0 & 1 & \\
\hline \multirow[t]{3}{*}{ Step 1} & USE & 0 & 88 & 3 & 96.7 \\
\hline & & 1 & 12 & 157 & 92.9 \\
\hline & Over & & & & 94.2 \\
\hline \multirow[t]{3}{*}{ Step 2} & USE & 0 & 81 & 10 & 89.0 \\
\hline & & 1 & 0 & 169 & 100.0 \\
\hline & Over & & & & 96.2 \\
\hline
\end{tabular}

a. The cut $v$ alue is .500

The final model with coeffiencents is presented below. The coefficient for trust is negative because the concept was operationalized using a reverse worded question.

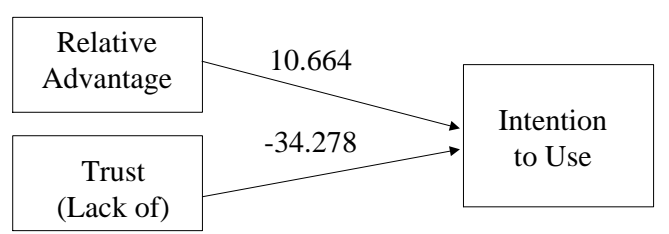

Figure 2. Significant Adoption Factors 


\section{Discussion}

\section{Significant Factors}

Relative advantage and trust have consistently been identified as important adoption constructs in the U.S. These constructs are also important factors to citizens of the U.K. Local agencies in the U.K. need to highlight the benefits of egovernment services compared to the other options for contacting the government. Local agencies also need to employ trust building strategies to increase citizen confidence in e-enabled services since a lack of trust decreases e-government adoption.

\section{Non-significant Factors}

Interestingly, Internet accessibility and skill were not significant determinants of e-government adoption in the U.K. In the United States, this divide is a major barrier to e-service adoption in both the public and private sector. However, perhaps the cultural differences between the two nations account for the absence of the ICT divide in U.K. e-government adoption. One of the major components of the digital divide in the U.S. is ethnicity, which may not be as salient in other cultures. The ICT divide may not be between those who have Internet access and those who do not. Perhaps, in the U.K., the type of Internet access (broadband vs. dial-up) is the discriminating factor. Future studies, should consider type of Internet access when comparing adoption across cultures.

\section{Implications for Practice}

Citizens who perceive the relative advantages of e-government services are more likely to adopt this innovation. The concept of relative advantage suggests that if e-government provides extra benefits, such as convenient access and prompt service, when compared to traditional means, then this technological advancement will be diffused throughout society. Considering the significance of this concept, it is imperative that local government in the U.K. informs citizens of the advantages of such services. Citizen knowledge of e-government services and their benefits is a vital part of e-government adoption. Choudrie and Dwivedi (2005) surveyed 358 citizens across the UK to examine public awareness of the national e-government gateway (www.direct.gov.uk). The authors found that only 
$6 \%$ of respondents from the research sample had registered with the gateway portal and $78 \%$ were not even aware of the government gateway for e-government services (Lee et al. 2005). Before citizens are able to appreciate the relative advantages of e-government services, they must first be aware of this electronic option. The government should implement a national e-government awareness initiative that highlights the services that are available and shares the benefits of them.

In addition to increasing awareness of the services and their advantages, the government needs to make sure services are implemented effectively. In this study, our participants commented on the inconveniences they experienced while using e-government services. Several citizens found that they had to phone the council to receive confirmation that their e-application or e-request was being processed. E-government systems should include an active status screen for each citizen's account. These systems should provide citizens with up-to-date, realtime information on the progress of their application. If a citizen has to use a traditional communications medium, such as phone or face-to-face, in addition to the e-government interface, the perceived relative advantage of e-services will be decreased (Hackney and Jones 2002).

In order to ensure relative advantage, government should focus their efforts on projects and strategies, particularly at the local level, which offer services that are value added to citizens in comparison to what is offered in the context of traditional methods of service. In this respect factors such as speed, efficiency and effectiveness of the e-services offered are all important aspects from a process improvement and cost saving perspective for the government and from a convenience perspective for the citizen. In the context of trust, proactive strategies and programs should be initiated to get the local communities involved in the decision making processes of e-government systems / service implementation. In this respect community forums and local council meetings (in the case of the UK) can be used to promote debate and better understanding of egovernment services among local citizens. In particular, the free ICT facilities offered in local libraries in the UK can also offer a useful platform for increasing e-government awareness among citizens. Furthermore, although local councils need to formulate their e-government plans in line with central government strategy, it is imperative that these plans are focused towards satisfying local 
citizens' needs and expectations rather than solely those of central government. Empirical research in the UK strongly suggests that succeeding at the local level is imperative for national level e-government success (Hackney and Jones 2002; Sarikas and Weerakkody 2007).

\section{Implications for Research}

The proposed model serves as an initial attempt to understand the salient predictors of e-government adoption in the U.K. To date few studies have explored the fundamental factors that impact e-government adoption in the U.K (Dwivedi et al. 2006). This study proposes a parsimonious model of egovernment adoption that incorporates adoption, trust and cultural influences. The results indicate that the U.K. may not be susceptible to the same cultural barriers as the U.S., such as lack of Internet accessibility and skill among a certain sect of the population. Future research should try to identify unique characteristics of U.K. citizens and culture that may have an impact on egovernment adoption. For instance, in the U.S., identification of socio-economic factors that widen the digital divide has led to numerous initiatives to reduce this barrier (Thomas and Streib 2003). In the U.K., research has identified a divide between broadband adopters and non-adopters (Dwivedi and Lal 2007). Given this context, we suggest that future research should explore how broadband access impacts the use of e-government services.

Future research should also include antecedents of both relative advantage and trust to present a more comprehensive model of e-government adoption. Benbasat and Barki (2007) suggest future adoption research should place more emphasis on the factors that impact relative advantage (Benbasat and Barki 2007). The literature also suggests that other factors, such as disposition to trust (Carter and Belanger 2005; McKnight et al. 2002), have an impact on trust. The proposed model highlights key predictors that have a direct effect on usage intentions. Future studies should expand the model to include both indirect and direct effects.

Future studies could also expand the concept of trust. Burgoon et al. (2002) view trust as one of four dimensions of credibility. They claim that trust includes character-related facets such as being truthful, trustworthy, sincere, responsible, and reliable. In the current study, we rely on Rotter's (1967) parsimonious yet robust view that trust is an expectancy that the promise of an individual or group can be relied upon. However, future researchers could expand 
the model by exploring the diverse dimensions of trust. Also, regarding trust, researchers could investigate the association of social network and trust. For instance, strength of ties is an aspect of social network that correlates to the degree of trust. This construct is measured by various criteria such as the length of time two actors spend together and the frequency of interaction (Kristiansen 2004). In addition to the aforementioned avenues for research that focus on electronic service delivery, it would also be beneficial to explore the role of trust in e-participation in the public sector.

\section{Limitations}

There are several limitations in this study. First, the sample was selected from one local council in London. Future research should attempt to obtain citizen responses from other areas in the country. Also, in interest of parsimony and obtaining as many participants as possible, we administered a very concise survey. Future studies should include additional constructs and items to present an even more comprehensive view of e-government adoption in the U.K (Pratchett 1999). Finally, since the independent and dependent variables come from the same respondents, there is a possibility that the results are biased due to common method variance.

\section{Conclusion}

The model proposed in this research illustrates the most salient predictors of e-government adoption in the U.K. It suggests that of the prevailing adoption constructs, relative advantage and trust are pertinent in both the U.S. and the U.K., while ICT adoption barriers such as access and skill may vary by culture. This study represents an initial attempt to identify key predictors of citizen intention to use e-government services in the U.K. The theoretical and practical justification for the research model presented in the paper is corroborated by drawing from literature that compares socio-cultural and technological similarities between the US and the UK. In particular, we use established e-government adoption factors in the US to assess adoption perspectives in the U.K. Although research exists that explores e-commerce adoption and broadband adoption, few studies to-date have explored e-government adoption in the U.K. from the citizen perspective. As egovernment grows in importance to government agencies and local citizens, it is imperative that we have a clear understanding of the salient influents on usage 
intention. As suggested by this study, these influents may differ according to a nation's demographics and cultural norms.

\section{Acknowledgement}

The authors wish to thank Mr. Jitin Mistry for administering the survey questionnaire in the United Kingdom and acknowledge the overall contribution made to this research.

\section{References}

Adeshara P., Juric R., Kuljis J., Paul R. (2004). A Survey of Acceptance of e-Government Services in the UK. International Conference on Information Technology Interfaces, Cavtat, Croatia.

Al-Sebie, M., Irani, Z. (2005). Technical and organisational challenges facing transactional egovernment systems: an empirical study. Electronic Government, an International Journal, 2(3), 247-276.

Becerra, M., Gupta, A. (1999). Trust Within the Organization: Integrating the Trust Literature with Agency Theory and Transaction Costs Economics. Public Administration Quarterly, 23(2), 177-203.

Belanger, F., Carter, L. (2006). The Digital Divide: An Empirical Investigation. Proceedings of the Hawaii International Conference on System Sciences, Kauai, Hawaii.

Benbasat, I., Barki, H. (2007). Quo Vadis TAM. Journal of the Association for Information Systems, 8(4), 211-218.

Bhattacherjee, A. (2002). Individual Trust In Online Firms: Scale Development and Initial trust. Journal of Management Information Systems, 19(1), 211-241.

Burgoon, J. K., Bonito, J. A., Ramirez, Jr. A., Dunbar, N. E., Kam, K., Fischer, J. (2002). Testing the Interactivity Principle: Effects of Mediation, Propinquity, and Verbal and Nonverbal Modalities in Interpersonal Interaction. Journal of Communication, 52(3) 657-677.

Carter, L., Belanger, F. (2005). The Utilization of E-government Services: Citizen Trust, Innovation and Acceptance Factors. Information Systems Journal, 15(1), 5-25.

Choudrie, J., Dwivedi, Y. (2005). A Survey of Citizens Adoption and Awareness of EGovernment Initiatives, The Government Gateway: A United Kingdom Perspective. EGovernment Workshop. Brunel University, West London.

comScore. (2006). 694 million people currently use the Internet Worldwide according to comScore networks. http://www.comscore.com/press/release.asp?press=849. Accessed 15 April 2008.

Cross, M. (2007). £5m e-government awareness campaign flops. The Guardian http://www.guardian.co.uk/technology/2006/oct/12/marketingandpr.newmedia. Accessed 15 April 2008.

Davis, F. D. (1989). Perceived usefulness, perceived ease of use, and user acceptance of information technology. MIS Quarterly, 13(3), 319-340.

SQW Limited and MORI Social Research Institute (2005). UK Online Centres and E-Government. Research Report RR632. U.K. Department for Education and Skills, London, U.K. http://www.dfes.gov.uk/research/data/uploadfiles/RR632.pdf. Accessed 17 February 2007.

Dwivedi Y., Choudrie J., Brinkman, W. (2006). Consumer Usage of Broadband in British Households. Int. J. Services and Standards, 2(4), 400-416.

Dwivedi, Y., Lal, B. (2007). Socio-economic determinants of broadband adoption. Industrial Management and Data Systems, 107(5), 654-671.

Dwivedi Y., Papazafeiropoulou A., Gharavi, H. (2006). Socio-Economic Determinants of Adoption of the Government Gateway Initiative in the UK. Electronic Government, 3(4), 404419.

European Union. (2004). United Nations Global e-Government Readiness Report 2004 - Towards Access for Opportunity. http://www.epractice.eu/document/2948. Accessed 11 September 2006. 
Ganesan, S., Hess, R. (1997). Dimensions and Levels of Trust: Implications for Commitment to a Relationship. Marketing Letters, 8(4), 439-448.

Gefen, D., Rose, G., Warkentin, M., Pavlou, P. (2005). Cultural Diversity and Trust in IT Adoption: A Comparison of USA and South African e-Voters._Journal of Global Information Management, 13(1), 54-78.

Gefen, D., E. Karahanna, Straub D. (2003). Trust and TAM in Online Shopping: An Integrated Model. MIS Quarterly, 27(1), 51-90.

Gilbert, D., Balestrini, P., Littleboy, D. (2004). Barriers and Benefits in the Adoption of Egovernment. International Journal of Public Sector Management, 17(4/5), 286-301.

Grazioli, S., Jarvenpaa, S. L. (2000). Perils of Internet Fraud: An Empirical Investigation of Deception and Trust with Experienced Internet Consumers. IEEE Transactions on Systems, Man, and Cybernetics-Part A: Systems and Humans, 30(4), 395-410.

Hackney, R., Jones, S. (2002). Towards E-government in the Welsh (UK) Assembly: an Information Systems Evaluation, ISOneWorld Conference and Convention, April 2002, Las Vegas, USA.

Hofstede, G. (2003). Geert Hofstede Cultural Dimensions. http://www.geerthofstede.com/hofstede dimensions.php?culture $1=95 \&$ culture $2=99$. Accessed 5 February 2008.

Holsapple, C., Sasidharan, S. (2005). The dynamics of trust in B2C e-commerce: a research model and agenda. Information Systems and E-Business Management, 3(4), 377-403.

Huang, Z. (2007). A comprehensive analysis of U.S. counties' e-Government portals: development status and functionalities. European Journal of Information Systems, 16: 149-164.

Jackson, L., von Eye A., Barbatsis G., Biocca F., Fitzgerald H., Yong Z. (2004). The Impact of Internet Use on the Other Side of the Digital Divide. Communications of the ACM, 47(7), 4347.

Jaeger, P. T. (2003). The endless wire: e-government as a global phenomenon. Government Information Quarterly, 20 (4), 323-331.

Jarvenpaa, S. L., Knoll, K., Leidner D. (1998). Is anybody out there? Antecedents of trust in global virtual teams. Journal of Management Information Systems, 14(4), 29-64.

Kablenet.com (2005). UK lagging on e-government. http://news.zdnet.co.uk/internet/0,1000000097,39198581,00.htm. Accessed 15 April, 2008

Kristiansen, S. (2004). Social Networks and Business Success -- the Role of Subcultures in an African Context. The American Journal of Economics and Sociology, 63(5), 1149-1171.

Lee, M. K. O., Turban, E. (2001). A Trust Model for Consumer Internet Shopping. International Journal of Electronic Commerce, 6(1), 75-91.

Lee, S. M., Tan, X., Trimi, S. (2005). Current practices of leading e-government countries.

Communications of the ACM, 48(10), 99-104.

Lieth, P., Morison, J. (2004). Communication and dialogue: what government websites might tell us about citizenship and governance. International Review of Law, computers \& Technology, 18 (1), 25-35.

Mayer, R. C., Davis, J., Schoorman F. (1995). An integrative model of organizational trust. Academy of Management Review, 20(3) 709-734.

McKnight, H., Choudhury, V., Kacmar C. (2002). Developing and Validating Trust Measures for E-commerce: An Integrative Typology. Information Systems Research, 13(3), 334-359.

McKnight, D. H., Cummings, L. L., Chervany N. (1998). Initial Trust Formation in New Organizational Relationships. Academy of Management Review, 23(3), 473-490.

Mossenburg, K., Tolbert, C., Stansbury, M. (2003). Virtual Inequality: Beyond the Digital Divide. George Washington University Press. Washington, D.C., George Washington University Press.

Navarra, D. D. and Cornford, T. (2003). A Policy making view of E-Government Innovations In Public governance, Proceedings Of The Ninth Americas Conference On Information Systems, Tampa, Florida.

Oxendine, A., Borgida, E., Sullivan, J.L., Jackson, M.S. (2003). The Importance of Trust and Community in Developing and Maintaining a Community Electronic Network. International Journal of Human-Computer Studies, 58(6), 671-196.

Pavlou, P. (2003). Consumer Acceptance of Electronic Commerce: Integrating Trust and Rsk with the Technology Acceptance Model. International Journal of Electronic Commerce, 7(3), 69103.

Pavlou, P. A. Fygenson, M. (2006). Understanding and Predicting Electronic Commerce Adoption: An Extension of the Theory of Planned Behavior, MIS Quarterly, 30(1), 115.

Plouffe, C., J. Julland, Vandenbosch M. (2001). Research Report: Richness Versus Parsimony in Modeling Technology Adoption Decisions-Understanding Merchant Adoption of a Smart Card-based Payment System. Information Systems Research, 12(2), 208-222. 
Pratchett, L. (1999). New technologies and the modernisation of local government: an analysis of biases and constraints. Public Administration, 77(4), 731-750.

Rogers, E. M. (2003). Diffusion of Innovation. New York, The Free Press.

Rotter, J. (1967). A New Scale for the Measurement of Interpersonal Trust. Journal of Personality, 35(4), 651-665.

Sarikas O., Weerakkody V. (2007). Realising Integrated E-Government Services: A UK Local Government Perspective. Transforming Government: People, Process and Policy, 1(2), 153173.

Shapiro, S. P. (1987). The social control of impersonal trust. American Journal of Sociology, 93(3), 623-658.

Tan, Y. H., Theon, W. (2001). Toward a generic model of trust for electronic commerce. International Journal of Electronic Commerce, 5(2), 61-74.

Thomas, J. C., Streib, G. (2003). The new face of government: Citizen-initiated contacts in the era of E-government. Journal of Public Administration Research and Theory, 13(1), 83 -102.

Van Slyke, C., Bélanger, F., Comunale, C. (2004). Adopting Business-to-Consumer Electronic Commerce: The Effects of Trust and Perceived Innovation Characteristics. The Data Base for Advances in Information Systems, 35(2), 32-49.

Venkatesch, V., Morris, M., Davis G., Davis F. (2003). User Acceptance of Information Technology: Toward a Unified View. MIS Quarterly, 27(3), 425-478.

Wang, Y. D., Emurian, H. H. (2005). An overview of online trust: Concepts, elements, and implications. Computers in Human Behavior, 21(5), 105-125.

Warkentin, M., Gefen, D., Pavlou P, Rose M. (2002). Encouraging citizen adoption of egovernment by building trust. Electronic Markets, 12(3), 157-162.

Weerakkody, V., Choudrie, J. (2005). Exploring E-Government in the UK: Challenges, Issues and Complexities. Journal of Information Science and Technology, 2(2), 26-44.

Welch, E. W., Hinnant, C.C., Moon, M. (2005). Linking Citizen Satisfaction with E-Government and Trust in Government. Journal of Public Administration Research and Theory, 15(3), 371 391.

Wellman, B., Haythornthwaite, C. (2002). The Internet in everyday life. Oxford, Blackwell.

Wright, N. (2002). The Economics of Privacy in the Information Age. Annual Meeting for the Academy of Marketing Studies.

Zucker, L.G. (1986). Production of trust: Institutional sources of economic structure, 1840-1920. Research in Organizational Behavior, 8(1), 53-111.

\section{AUTHOR BIOS}

Lemuria Carter is an Assistant Professor at North Carolina Agricultural and

Technical State University. She received her Ph.D. in Accounting and

Information Systems from Virginia Polytechnic Institute and State University

(Virginia Tech). Her research focuses on technology adoption, electronic-

government and Internet voting. She has published articles in several reputable, refereed journals including Communications of the ACM, Journal of Strategic

Information Systems, and Information Systems Journal. Her research is also included in various international conference proceedings, including the Americas

Conference on Information Systems (AMCIS) and the Hawaiian International Conference on System Sciences (HICSS).

Vishanth Weerakkody is a Lecturer in Strategic Information Systems at the School of Information Systems, Computing and Mathematics at Brunel University in the UK. He holds an MSc in Business Systems Analysis and Design and a PhD 
in Business Process and Information Systems Reengineering. His current research interests include e-government, cross-organisational process redesign and technology adoption. He has guest-edited special issues of leading journals on these themes and he is the Associate Editor for a number of leading journals. He has also held various IT positions in multinational organisations and his final appointment in industry was as a Methods and Process Analyst at IBM UK. Dr Weerakkody is a Chartered IT professional, Member of the British Computer Society and Fellow of the UK Higher Education Academy. 